\section{ESTABILIDADE DE FORMULAÇÃO DERMOCOSMÉTICA CONTENDO EXTRATO DE PELARGONIUM GRAVEOLENS}

\author{
Daniela Gelaleti'; \\ Isabella Stefanov Galvão'; Mayara Muniz \\ Lourenço Batista'; \\ Micheli Felix'; \\ Victória Fernandes dos Santos'; \\ Maira Jardim; \\ Carlos Rocha Oliveira ${ }^{3}$; \\ Valéria Maria de Souza Antunes ${ }^{3}$.
}

1Universidade Anhembi Morumbi

${ }^{2}$ WNF - Indústria e comércio

${ }^{3}$ Professor Universidade Anhembi Morumbi

Recebido em novembro de 2018.

Aceito em janeiro de 2019.

\section{Resumo}

O Pelargonium graveolens $L$. conhecido popularmente como gerânio, é uma planta aromática e perene que apresenta diversas propriedades e indicações terapêuticas. São elas: ação antifúngica, adstringente, de combate a acne, antissépti$\mathrm{ca}$, antienvelhecimento e relaxante. Sendo assim, considerando suas diversas indicações para tratamentos relacionados a pele e tendo em vista sua aplicação na fabricação de cosméticos, o presente trabalho avaliou a estabilidade do extrato bruto hidroalcoólico de Pelargonium graveolens $L$ em diferentes concentrações aplicado em base dermatológica simples de creme aniônico durante 90 dias seguidos. Conforme o Guia de Estabilidade de Produtos Cosméticos da ANVISA (Agência Nacional de Vigilância Sanitária), a base dermatológica foi exposta a diversos testes. São eles: à temperatura ambiente; sob a luz solar; incubada em estufa e em geladeira, a fim de detectar algum tipo de alteração no produto durante esse período em que os testes foram realizados. Neste sentido, os resultados apresentados sugerem que mesmo em diversas concentrações o extrato hidroalcóolico quando incorporado a uma base dermatológica permanece estável e os resultados nos permitem concluir que a fabricação de cosméticos utilizando Pelargonium graveolens L. é possível, bem como que o produto mantém suas características iniciais e que pode ser utilizado como base para possíveis dermocosméticos com ações cutâneas.

Palavras Chaves: Pelargonium graveolens L.; Gerânio; Cosméticos; Estabilidade Acelerada.

\section{Introdução}

Denominada como Pelargonium graveolens L., popularmente conhecida como Gerânio ou Malvacheirosa e pertencente à família Geraniaceae, trata-se de uma planta aromática e perene, originária da África do Sul (SIMON ET AL,1984). Por ter um aroma agradável e que se assemelha ao aroma de pétalas de rosas, tem uso na produção de cosméticos (SAXENA ET AL,2000).

O Pelargonium gravoelens $\mathrm{L}$. pode ser cultivado em climas tropicais, subtróficos, temperados e mediterrânicos por se tratar de uma espécie altamente maleável. Prefere os solos drenados, aerados, silicosos aos francos. Floresce em condições ensolaradas e possui certa tolerância ao frio e a seca, mesmo se tratando de uma espécie sensível. (SIMON ET AL,1984)

No extrato da planta é possível localizar fitoquímicos fenólicos, incluindo ácidos fenólicos, flavonóides, taninos, cumarinas. Isso explica suas propriedades antibacterianas. (KOLODZIEJ et al., 2003; SEIDEL; TAYLOR, 2004)

Suas folhas são simples, alternas, palmatilobadas; têm lobos pinatífidos, ou 7 lobúlos recortados da cor verde clara com nervuras salientes e aromáticas (SI- 
MON ET AL,1984). Apresentam atividade antimicrobiana e antifúngica. (SHIN,2003).

As flores que surgem no Pelargonium são pequenas, pediceladas, brancas com listas róseas, dispostas em umbela. (MILLER,2002)

Em algumas de suas propriedades é possível descrever sua ação adstringente, antisséptica, antifúngica. Além de suas propriedades anti-inflamatórias e imunomoduladoras. (Han,X.,Beaumont,C.,Stevens,N., 2017)

É possível, ainda, utilizá-lo para tratamentos na pele como cuidados externos, tendo como exemplo o cuidado da acne, devido a suas grandes propriedades antissépticas que purificam e suavizam a pele, devido a diminuição da oleosidade da pele (ABURJAI, T.; NATSHEH, F,2000)

As oxidações químicas e enzimáticas envolvem a formação de radicais livres que tem papel fundamental no envelhecimento cutâneo devido aos danos causados ao DNA. (Hidtata, L.,Sato M., Santos C., 2004). A atividade antioxidante apresentada pelo $P e$ largonium graveolens $L$. está diretamente relacionada a diminuição de radicais livres, que por consequência pode auxiliar no tratamento do envelhecimento cutâneo. (Gupta, R., Singh, A., \& Pandey, R.,2016).

$\mathrm{O}$ presente trabalho teve como intuito analisar a estabilidade da formulação juntamente com o extrato do Pelargonium graveolens $L$. em base dermatológica, com finalidade de investigar a possível compatibilidade do extrato hidroalcoólico na base constituída com creme aniônico, para produção de possíveis Dermocosmeticos que possam ser desenvolvidos para utilizações e aplicações referentes as propriedades apresentadas pela espécie.

\section{Metodologia}

Esse trabalho foi desenvolvido gentilmente em parceria com a indústria WNF com acompanhamento diário de farmacêuticos em paralelo a alunas da Universidade Anhembi Morumbi. O Princípio do trabalho é a avaliação da estabilidade acelerada do extrato hidroalcoólico do Pelargonium Graveolens L. em base dermatológica. Os testes de estabilidade acelerada, em que constituiu na avaliação de $\mathrm{pH}$ e a resistência do creme em temperaturas alternadas, foram realizados durante 90 dias e as avaliações foram feitas de acordo com o Guia de estabilidade de produtos cosméticos da ANVISA (Agência Nacional de Vigilância Sanitária).

A base utilizada foi a cera auto emulsionante aniônica, descrita abaixo, com propriedades umectantes. O processo de manipulação da formulação foi dividido em 2 fases, sendo a fase aquosa vertida sob a fase oleosa após serem aquecidas a $70^{\circ} \mathrm{C}$. Em seguida, foi emulsionada sob agitação constante até completo resfriamento, apresentando cor branco opaca.

As amostras foram acondicionadas com uma quantidade de produto suficiente para as avaliações necessárias em frascos de vidros neutros, transparente, com tampa que garantiu uma boa vedação.

$\mathrm{O}$ teste de estabilidade acelerada teve como designo aumentar a velocidade de degradação química e/ou alterações físicas no produto pela utilização de condições drásticas de armazenamento com o objetivo de fornecer dados para prever a estabilidade do produto, tempo de vida útil e compatibilidade da formulação com o material de acondicionamento.

\section{Materiais}

\begin{tabular}{|l|c|}
\hline \multicolumn{2}{|c|}{ Fase A } \\
\hline Edta & $2 \mathrm{~g}$ \\
\hline Nipagin & $2 \mathrm{~g}$ \\
\hline Propilenoglicol & $60 \mathrm{~g}$ \\
\hline Água purificada & $1.612 \mathrm{~g}$ \\
\hline \multicolumn{2}{|c|}{ Fase B } \\
\hline $\begin{array}{l}\text { Cera Auto emulsionante Aniônica } \\
\text { - Lanette }\end{array}$ & $240 \mathrm{~g}$ \\
\hline Nipazol & $80 \mathrm{~g}$ \\
\hline Bht & $4 \mathrm{~g}$ \\
\hline
\end{tabular}

Utilizou-se frasco vidro incolor; e na embalagem primária da amostra: vidro cristal com tampa plástica (matéria-prima da embalagem). Para realização de todas as análises utilizou-se a aparelhagem como geladeira, estufas e pHmetro, todos devidamente calibrados segundo a Portaria n 0348 de 18 de agosto de 1997 que regulamenta as boas práticas de fabricação e 
controle para produtos de higiene pessoal, cosméticos e perfumes.

O pHmeto foi utilizado para controle e monitoramento de $\mathrm{pH}$ do creme aniônico, pois ele é um instrumento indicativo de acidez, neutralidade ou alcalinidade.
O produto utilizado foi a base de emulsão aniônico incorporada com o extrato de Pelargonium Graveolens $L$. nas concentrações $0,5 \%, 1,5 \%$ e $3 \%$, com data de fabricação no dia 06/03/2018; sua forma física é líquida e límpida.

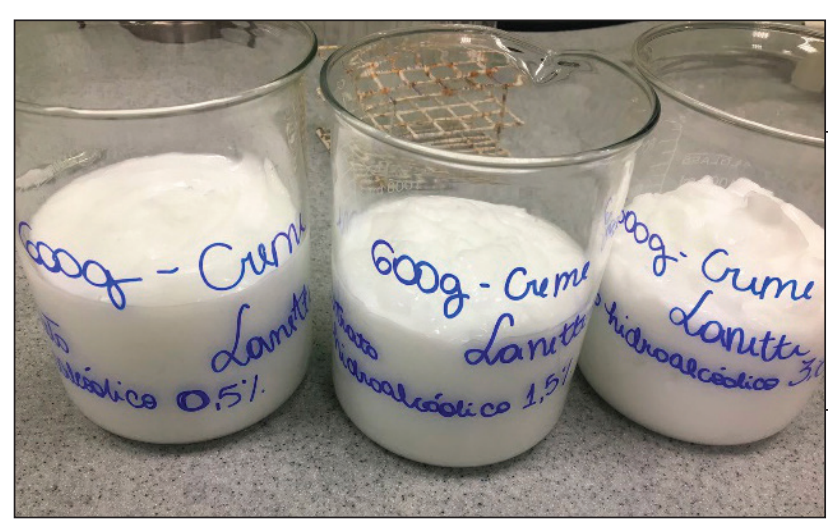

\section{Resultados}

O Estudo de Estabilidade Acelerada teve como data de início 06/03/2018 e término em 04/06/2018, em que os ensaios e testes foram realizados nos seguintes intervalos de tempos: mês zero (06/03/2018); 15 dias (21/03/2018); 30 dias (05/04/2018); 60 dias (07/05/2018) e 90 dias (04/06/2018).

As amostras iniciaram a partir da fórmula de referência, denominada como padrão, no qual misturou-se os componentes descritos, homogeneizou-se, deixando-os em repouso.

Todos os frascos de vidros incolores foram enva-
Figura 1: Imagem ilustrativa do creme aniônico em suas diferentes concentrações incorporado ao extrato do Perlagonium Graveolens L. antes do inicio dos testes de estabilidade acelerada, com período de 90 dias.

\begin{tabular}{|l|l|l|l|}
\hline $\begin{array}{c}\text { Concentrações do creme aniônico com extrato de } \\
\text { Perlagonium Graveolens L. }(\%)\end{array}$ & $0.5 \%$ & $1.5 \%$ & $3.0 \%$ \\
\hline Tempo zero $(\mathrm{pH})$ & 5.60 & 5.44 & 5.32 \\
\hline Tempo 15 dias $(\mathrm{pH})$ & 5.21 & 5.08 & 4.77 \\
\hline Tempo 30 dias $(\mathrm{pH})$ & 4.81 & 4.77 & 4.37 \\
\hline Tempo 60 dias $(\mathrm{pH})$ & 5.57 & 5.10 & 4.64 \\
\hline Tempo 90 dias $(\mathrm{pH})$ & 5.57 & 5.23 & 5.21 \\
\hline Variação média $( \pm)$ & 5.35 & 5.13 & 4.67 \\
\hline Desvio padrão $( \pm)$ & 0.3430 & 0.2444 & 0.3970 \\
\hline
\end{tabular}

Figura 2: Valores de variação de pH em função do tempo. Resultados obtidos através do teste de estabilidade acelerada. 


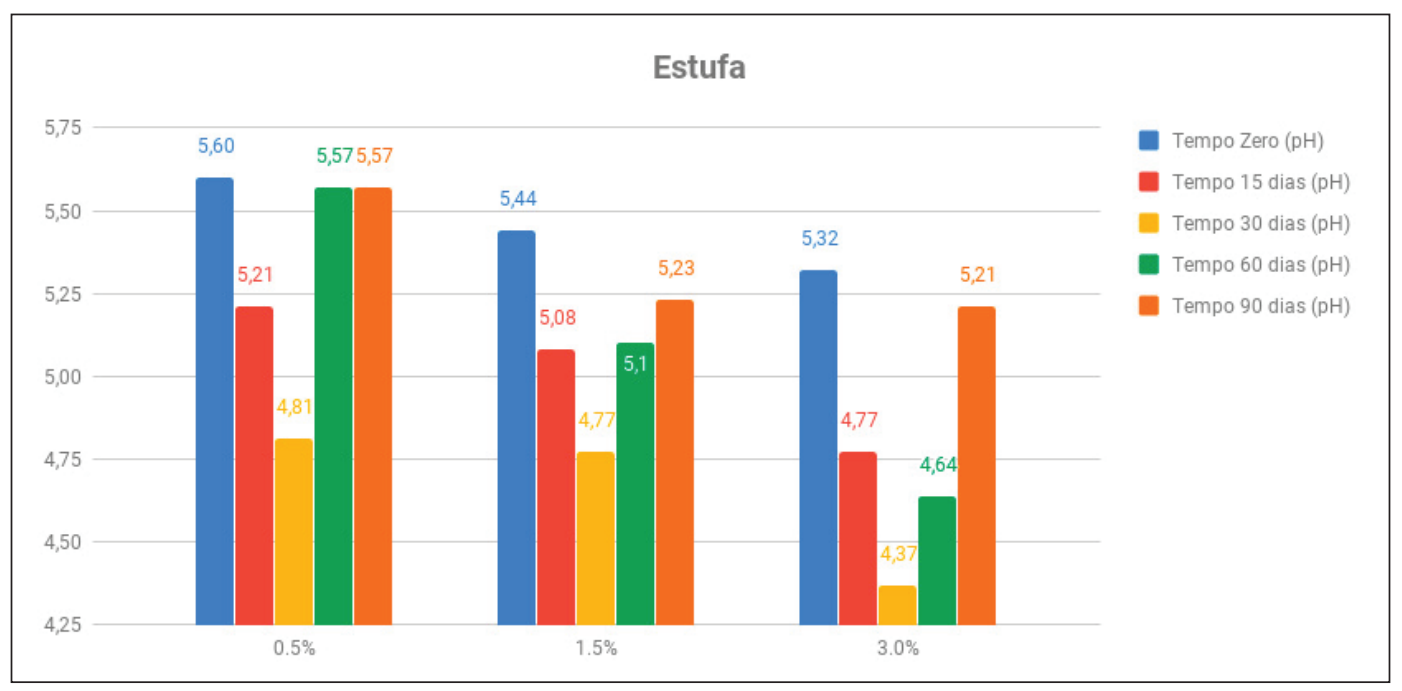

Figura 3: Gráfico demonstrativo com todos as concentrações informando os valores da variação do pH do creme aniônico de acordo com a exposição a estufa ao longo de 90 dias.

Acima são apresentados os resultados referentes as variações do $\mathrm{pH}$ do creme aniônico em três concentrações diferentes $(0.5 \%, 1.5 \%$ e $3.0 \%)$ que estavam em estufa por 90 dias. Os resultados foram colhidos nos dias: Zero, 15 dias, 30 dias, 60 dias e 90 dias, e suas variações foram as apresentadas em forma de gráfico e tabela. No gráfico, as abcissas são as concentrações de extrato hidroalcoólico de Pelargonium graveolens em cada creme, e as ordenadas são as variações de Ph, todas as colunas azuis são referentes ao tempo Zero, as colunas vermelhas são referentes ao tempo 15 dias, as colunas amarelas são referentes ao tempo 30 dias, as colunas verdes são referentes ao tempo 60 dias e as colunas laranjas são referentes ao tempo 90 dias, a diferença de tamanho apresentada entre elas caracteriza a variação de $\mathrm{pH}$ do creme aniônico.

$\mathrm{Na}$ tabela, as colunas são referentes as concentrações de extrato hidroalcoólico de Pelargonium Graveolens em cada creme, e as linhas são referentes ao tempo e ao Ph colhido em cada dia, temos também a média a qual cada concentração variou durante os dias de teste e também o desvio padrão apresentado por cada concentração após os 90 dias em estufa.

Após uma amostra de cada concentração $(0,5 \%$, $1,5 \%$ e $3 \%)$ do produto foi encubada na geladeira a uma temperatura de $2^{\circ} \mathrm{C}$ a $8^{\circ} \mathrm{C}$, por um período de 90 dias, demonstrando os seguintes resultados:

\begin{tabular}{|l|l|l|l|}
\hline $\begin{array}{c}\text { Concentrações do creme aniônico com extrato de } \\
\text { Perlagonium Graveolens L. }(\%)\end{array}$ & $0.5 \%$ & $1.5 \%$ & $3.0 \%$ \\
\hline Tempo zero $(\mathrm{pH})$ & 5.60 & 5.44 & 5.32 \\
\hline Tempo 15 dias $(\mathrm{pH})$ & 5.32 & 5.07 & 4.85 \\
\hline Tempo 30 dias $(\mathrm{pH})$ & 4.77 & 4.88 & 4.28 \\
\hline Tempo 60 dias $(\mathrm{pH})$ & 5.00 & 4.77 & 4.59 \\
\hline Tempo 90 dias $(\mathrm{pH})$ & 5.02 & 4.98 & 4.21 \\
\hline Variação média $( \pm)$ & 5.14 & 5.03 & 4.65 \\
\hline Desvio padrão $( \pm)$ & 0.3220 & 0.2560 & 0.4535 \\
\hline
\end{tabular}

Figura 4: Valores de variação de pH em função do tempo. Resultados obtidos através do teste de estabilidade acelerada. 


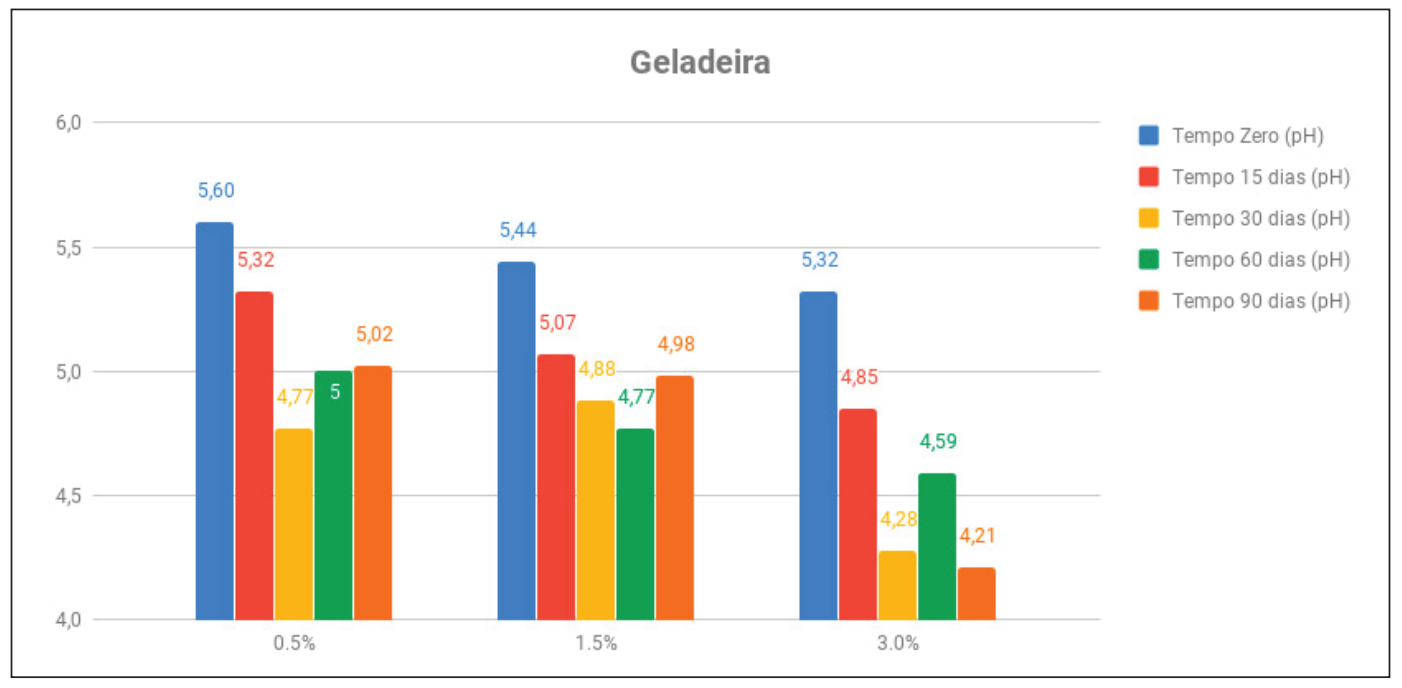

Figura 5: Gráfico demonstrativo com todos as concentrações informando os valores da variação do pH do creme aniônico de acordo com a exposição a geladeira ao longo de 90 dias.

Acima são apresentados os resultados referentes as variações do $\mathrm{pH}$ do creme aniônico em três concentrações diferentes $(0.5 \%, 1.5 \%$ e $3.0 \%)$ que estavam em geladeira por 90 dias. Os resultados foram colhidos nos dias: Zero, 15 dias, 30 dias, 60 dias e 90 dias, e suas variações foram as apresentadas em forma de gráfico e tabela. No gráfico, as abcissas são as concentrações de extrato hidroalcoólico de Pelargonium graveolens em cada creme, e as ordenadas são as variações de $\mathrm{Ph}$, todas as colunas azuis são referentes ao tempo Zero, as colunas vermelhas são referentes ao tempo 15 dias, as colunas amarelas são referentes ao tempo 30 dias, as colunas verdes são referentes ao tempo 60 dias e as colunas laranjas são referentes ao tempo 90 dias, a diferença de tamanho apresentada entre elas caracteriza a variação de $\mathrm{pH}$ do creme aniônico.

$\mathrm{Na}$ tabela, as colunas são referentes as concentrações de extrato hidroalcoólico de Pelargonium Graveolens em cada creme, e as linhas são referentes ao tempo e ao $\mathrm{Ph}$ colhido em cada dia, temos também a média a qual cada concentração variou durante os dias de teste e também o desvio padrão apresentado por cada concentração após os 90 dias em geladeira.

Em paralelo uma amostra de cada concentração $(0,5 \%, 1,5 \%$ e $3 \%)$ do produto foi deixada a temperatura ambiente no período de 90 dias, informando os resultados abaixo:

\begin{tabular}{|l|l|l|l|}
\hline $\begin{array}{c}\text { Concentrações do creme aniônico com extrato de } \\
\text { Perlagonium Graveolens L. }(\%)\end{array}$ & $0.5 \%$ & $1.5 \%$ & $3.0 \%$ \\
\hline Tempo zero $(\mathrm{pH})$ & 5.60 & 5.44 & 5.32 \\
\hline Tempo 15 dias $(\mathrm{pH})$ & 5.31 & 5.02 & 4.98 \\
\hline Tempo 30 dias $(\mathrm{pH})$ & 4.74 & 4.64 & 4.34 \\
\hline Tempo 60 dias $(\mathrm{pH})$ & 5.02 & 4.75 & 4.27 \\
\hline Tempo 90 dias $(\mathrm{pH})$ & 5.00 & 4.83 & 4.67 \\
\hline Variação média $( \pm)$ & 5.14 & 4.94 & 4.71 \\
\hline Desvio padrão $( \pm)$ & 0.3295 & 0.3140 & 0.4407 \\
\hline
\end{tabular}

Figura 6: Valores de variação de pH em função do tempo. Resultados obtidos através do teste de estabilidade acelerada. 


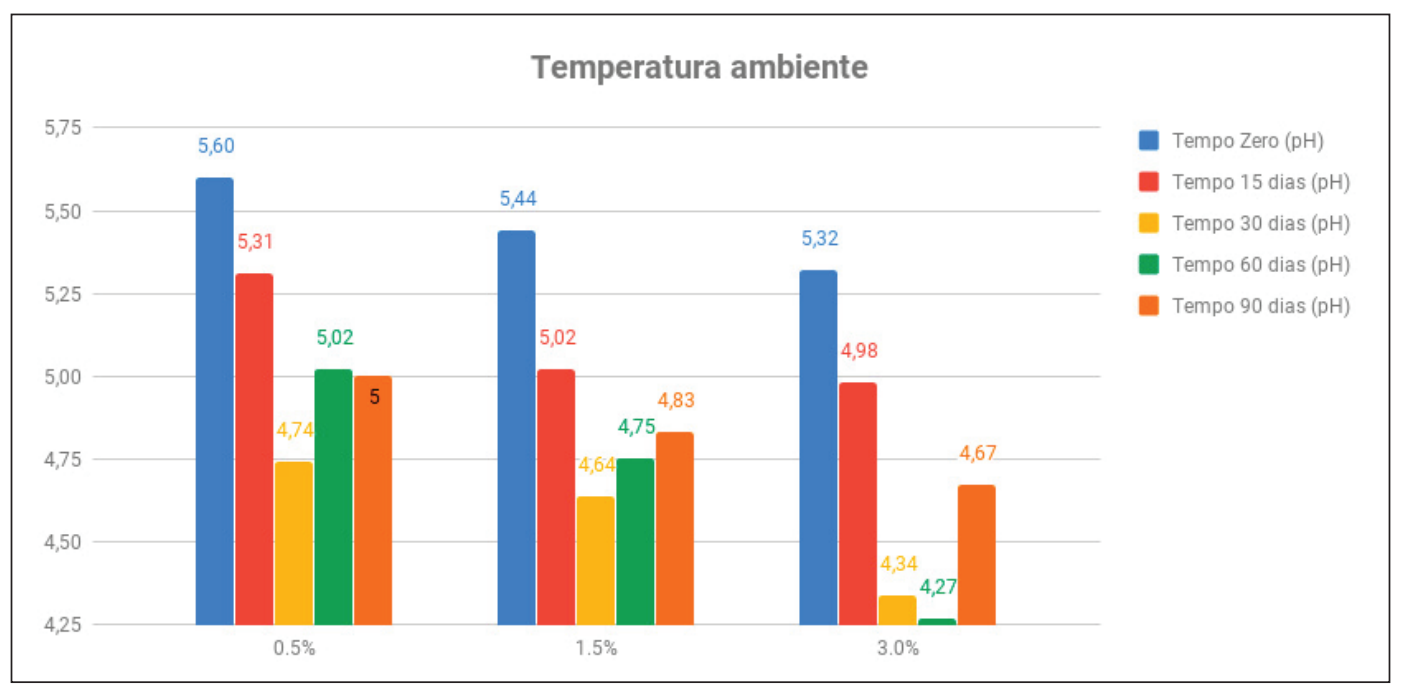

Figura 7: Gráfico demonstrativo com todos as concentrações informando os valores da variação do pH do creme aniônico de acordo com a exposição a temperatura ambiente ao longo de 90 dias.

Acima são apresentados os resultados referentes as variações do $\mathrm{pH}$ do creme aniônico em três concentrações diferentes $(0.5 \%, 1.5 \%$ e $3.0 \%)$ que estavam em temperatura ambiente por 90 dias. Os resultados foram colhidos nos dias: Zero, 15 dias, 30 dias, 60 dias e 90 dias, e suas variações foram as apresentadas em forma de gráfico e tabela. No gráfico, as abcissas são as concentrações de extrato hidroalcoólico de Pelargonium graveolens em cada creme, e as ordenadas são as variações de $\mathrm{Ph}$, todas as colunas azuis são referentes ao tempo Zero, as colunas vermelhas são referentes ao tempo 15 dias, as colunas amarelas são referentes ao tempo 30 dias, as colunas verdes são referentes ao tempo 60 dias e as colunas laranjas são referentes ao tempo 90 dias, a diferença de tamanho apresentada entre elas caracteriza a variação de $\mathrm{pH}$ do creme aniônico.

$\mathrm{Na}$ tabela, as colunas são referentes as concentrações de extrato hidroalcoólico de Pelargonium Graveolens em cada creme, e as linhas são referentes ao tempo e ao $\mathrm{pH}$ colhido em cada dia, temos também a média a qual cada concentração variou durante os dias de teste e também o desvio padrão apresentado por cada concentração após os 90 dias em temperatura ambiente.

Uma amostra de cada concentração $(0,5 \%, 1,5 \%$ e $3 \%$ ) do produto foi submetida à luz solar um período de 90 dias, demonstrando os seguintes resultados:

\begin{tabular}{|l|l|l|l|}
\hline $\begin{array}{c}\text { Concentraçães do creme aniônico com extrato de } \\
\text { Perlagonium Graveolens L. }(\%)\end{array}$ & $0.5 \%$ & $1.5 \%$ & $3.0 \%$ \\
\hline Tempo zero $(\mathrm{pH})$ & 5.60 & 5.44 & 5.32 \\
\hline Tempo 15 dias $(\mathrm{pH})$ & 5.13 & 5.00 & 4.77 \\
\hline Tempo 30 dias $(\mathrm{pH})$ & 4.65 & 4.64 & 3.85 \\
\hline Tempo 60 dias $(\mathrm{pH})$ & 4.83 & 4.35 & 3.95 \\
\hline Tempo 90 dias $(\mathrm{pH})$ & 5.05 & 4.55 & 4.02 \\
\hline Variação média $( \pm)$ & 5.05 & 4.80 & 4.38 \\
\hline Desvio padrão $( \pm)$ & 0.3597 & 0.4301 & 0.6386 \\
\hline
\end{tabular}

Figura 8: Valores de variação de $\mathrm{pH}$ em função do tempo. Resultados obtidos através do teste de estabilidade acelerada. 


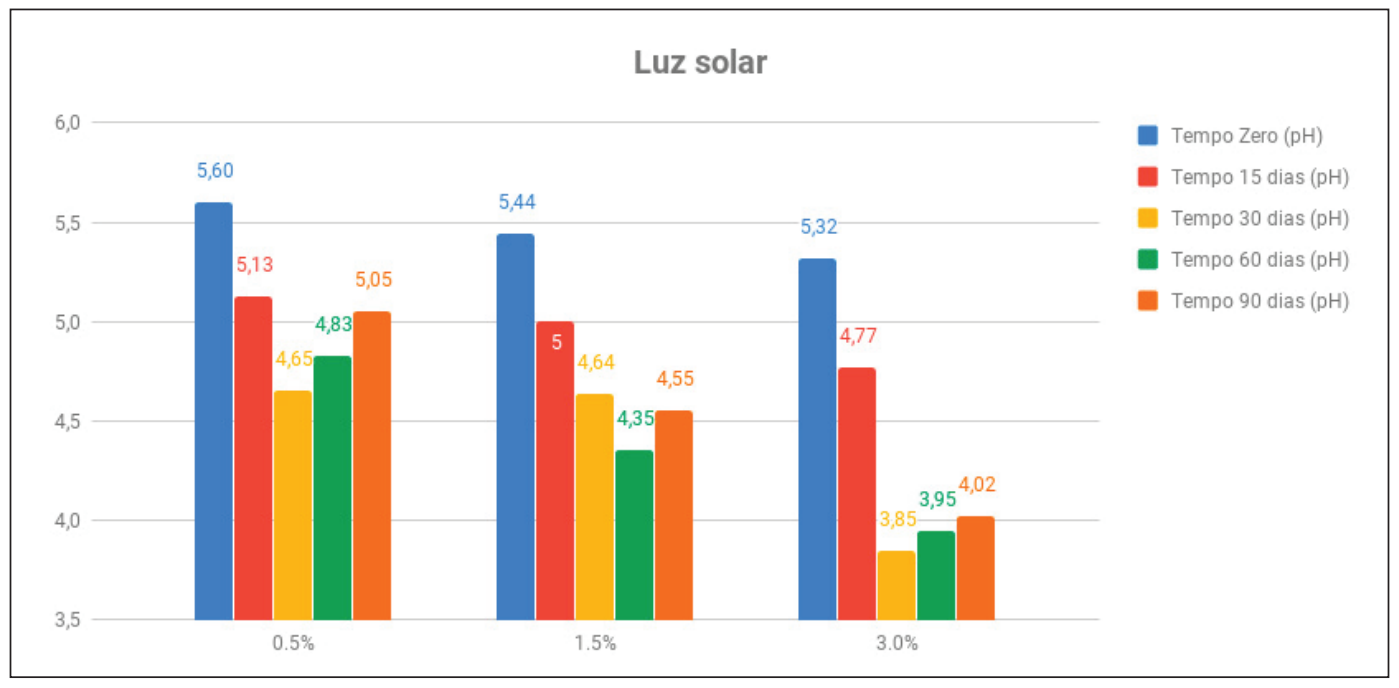

Figura 9: Gráfico demonstrativo com todos as concentrações informando os valores da variação do $\mathrm{pH}$ do creme aniônico de acordo com a exposição da luz solar ao longo de 90 dias.

Acima são apresentados os resultados referentes as variações do $\mathrm{pH}$ do creme aniônico em três concentrações diferentes $(0.5 \%, 1.5 \%$ e $3.0 \%)$ que estavam em luz solar por 90 dias. Os resultados foram colhidos nos dias: Zero, 15 dias, 30 dias, 60 dias e 90 dias, e suas variações foram as apresentadas em forma de gráfico e tabela. No gráfico, as abcissas são as concentrações de extrato hidroalcoólico de Pelargonium graveolens em cada creme, e as ordenadas são as variações de $\mathrm{pH}$ todas as colunas azuis são referentes ao tempo Zero, as colunas vermelhas são referentes ao tempo 15 dias, as colunas amarelas são referentes ao tempo 30 dias, as colunas verdes são referentes ao tempo 60 dias e as colunas laranjas são referentes ao tempo 90 dias, a diferença de tamanho apresentada entre elas caracteriza a variação de $\mathrm{pH}$ do creme aniônico.

$\mathrm{Na}$ tabela, as colunas são referentes as concentrações de extrato hidroalcoólico de Pelargonium Graveolens em cada creme, e as linhas são referentes ao tempo e ao $\mathrm{pH}$ colhido em cada dia, temos também a média a qual cada concentração variou durante os dias de teste e também o desvio padrão apresentado por cada concentração após os 90 dias em luz solar.

Uma amostra de cada concentração $(0,5 \%, 1,5 \%$ e $3 \%)$ do produto foi submetida a ciclos de intervalo de 24 horas cada, alternados entre geladeira a $2^{\circ} \mathrm{C}-8^{\circ} \mathrm{C}$, e estufa a $50^{\circ} \mathrm{C}$, demonstrando os seguintes resultados:

\begin{tabular}{|l|l|l|l|}
\hline $\begin{array}{c}\text { Concentrações do creme aniônico com extrato de } \\
\text { Perlagonium Graveolens L. }(\%)\end{array}$ & $0.5 \%$ & $1.5 \%$ & $3.0 \%$ \\
\hline Tempo zero $(\mathrm{pH})$ & 5.60 & 5.44 & 5.32 \\
\hline Tempo 15 dias $(\mathrm{pH})$ & 5.39 & 5.10 & 4.91 \\
\hline Tempo 30 dias $(\mathrm{pH})$ & 4.74 & 5.28 & 4.37 \\
\hline Tempo 60 dias $(\mathrm{pH})$ & 5.55 & 5.00 & 4.24 \\
\hline Tempo 90 dias $(\mathrm{pH})$ & 5.45 & 5.07 & 5.02 \\
\hline Variação média $( \pm)$ & 5.34 & 5.17 & 4.77 \\
\hline Desvio padrão $( \pm)$ & 0.3486 & 0.1792 & 0.4542 \\
\hline
\end{tabular}

Figura 10: Valores de variação de $\mathrm{pH}$ em função do tempo. Resultados obtidos através do teste de estabilidade acelerada. 


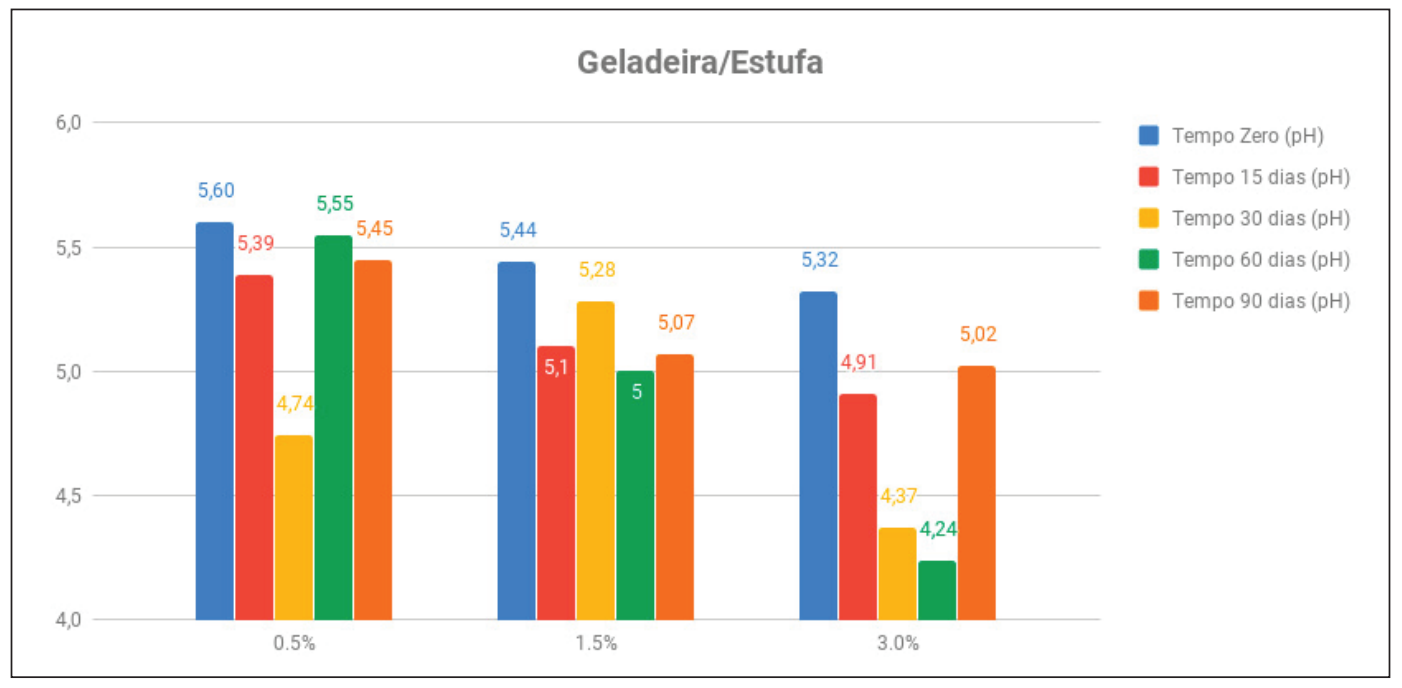

Figura 11: Gráfico demonstrativo com todos as concentrações informando os valores da variação do $\mathrm{pH}$ do creme aniônico de acordo com a exposição a temperaturas de geladeira/estufa ao longo de 90 dias.

Acima são apresentados os resultados referentes as variações do $\mathrm{pH}$ do creme aniônico em três concentrações diferentes $(0.5 \%, 1.5 \%$ e $3.0 \%)$ que estavam em ciclos alternados entre geladeira e estufa por 90 dias. Os resultados foram colhidos nos dias: Zero, 15 dias, 30 dias, 60 dias e 90 dias, e suas variações foram as apresentadas em forma de gráfico e tabela. No gráfico, as abcissas são as concentrações de extrato hidroalcoólico de Pelargonium graveolens em cada creme, e as ordenadas são as variações de $\mathrm{Ph}$, todas as colunas azuis são referentes ao tempo Zero, as colunas vermelhas são referentes ao tempo 15 dias, as colunas amarelas são referentes ao tempo 30 dias, as colunas verdes são referentes ao tempo 60 dias e as colunas laranjas são referentes ao tempo 90 dias, a diferença de tamanho apresentada entre elas caracteriza a variação de $\mathrm{pH}$ do creme aniônico.

$\mathrm{Na}$ tabela, as colunas são referentes as concentrações de extrato hidroalcoólico de Pelargonium Graveolens em cada creme, e as linhas são referentes ao tempo e ao $\mathrm{pH}$ colhido em cada dia, temos também a média a qual cada concentração variou durante os dias de teste e também o desvio padrão apresentado por cada concentração após os 90 dias em ciclos alternados entre geladeira e estufa.

\begin{tabular}{|l|l|l|l|}
\hline $\begin{array}{c}\text { Concentrações do creme aniôni- } \\
\text { co com extrato de Perlagonium } \\
\text { Graveolens L. (\%) }\end{array}$ & $0.5 \%$ & $1.5 \%$ & $3.0 \%$ \\
\hline Valores após 90 & Manteve-se estável & $\begin{array}{l}\text { Algumas alterações, } \\
\text { porém estável. }\end{array}$ & $\begin{array}{l}\text { Formação de grâ- } \\
\text { nulos e consistência } \\
\text { sólida, porém estável }\end{array}$ \\
\hline Satisfatórios-Insatisfatórios & Satisfatório & Satisfatório & Satisfatório \\
\hline
\end{tabular}

Figura 12: Concentrações do creme aniônico com extrato de Perlagonium Graveolens L

\section{Discussão}

Por apresentarem propriedades reconhecidamente terapêuticas, os fitoterápicos, e mais comumente, os extratos vegetais, vêm sendo incorporados em formulações dermocosméticas (Pianovski, 2008). Contudo, em relação ao controle de qualidade, a inserção destes insumos vegetais ativos em formulações magistrais 

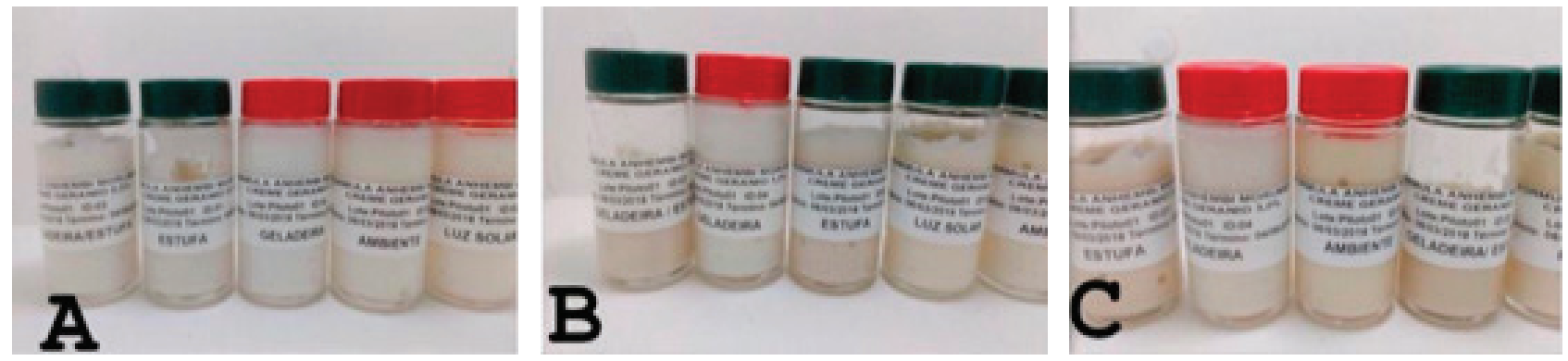

Figura 13: A-Imagem referente as amostras na concentração 0,5\% após 90 dias. Analises por meio do teste estatístico, test-t. B-Imagem referente as amostras na concentração 1,5\% após 90 dias. Analises por meio teste estatístico, test-t. C-Imagem referente as amostras na concentração 3,0\% após 90 dias. Analises por meio teste estatístico, test-t.

ou industriais, requer maior controle de qualidade e padronização na produção destas formulações, ressaltando a importância das características físicoquímicas destes produtos (List, 1989). Ainda neste contexto, o adequado desenvolvimento de formas farmacêuticas, revela importante avanço sobre utilização de produtos naturais (Rolim et.al. 2005), mesmo que haja uma possível variabilidade entre os lotes, exista também uma margem de segurança, possibilitando a obtenção de resultados reprodutíveis e dessa forma garantir sua eficácia (Newall, 1999).

Assim, este trabalho procurou avaliar a estabilidade de uma formulação dermocosmética contendo extrato hidroalcoolico de gerânio, por meio do estudo de estabilidade acelerada. Os resultados indicaram uma boa estabilidade das formulações, principalmente e de forma compreensível, nas que tinham a menor concentração do extrato de gerânio. Ainda assim, as formulações com concentrações de $1.5 \%$ do extrato de gerânio, demonstrou alteração de coloração após 30 dias de teste, no qual sua coloração inicial foi de branco a bege claro e, após, para coloração marrom claro. Contudo, outros aspectos, como $\mathrm{pH}$, mantiveram-se estáveis após terem sido submetidos a todos os estresses no período de 90 dias, concluindo, assim, resultados satisfatórios.

Entretanto, a última concentração da emulsão aniônica analisada foi de $3.0 \%$, em que demonstrou formação de grânulos e consistência sólida, mas outros aspectos, como $\mathrm{pH}$, mantiveram-se estáveis e sem alterações no período de 90 dias, concluindo, assim, resultados satisfatórios.

\section{Conclusão}

Os resultados obtidos no presente estudo indicaram que o extrato hidroalcoolico de Perlagonium Graveoleons L. demonstrou boa compatibilidade com a emulsão aniônica utilizada durante o período de 90 dias, tempo utilizado para a realização do teste de estabilidade acelerada. Neste sentido, é possível sugerir que a formulação desenvolvida apresentou resultados satisfatórios em relação a sua estabilidade, uma vez que, ao término dos testes, as amostras não demonstraram alterações significativas em relação aos parâmetros avaliados, como o $\mathrm{pH}$, viscosidade, entre outros. No entanto, estudos complementares envolvendo outros tipos de estabilidade, devem ser realizados a fim de se obter informações mais detalhadas do produto.

\section{Referências}

Agência Nacional de Vigilância Sanitária. Guia de estabilidade de produtos cosméticos. Séries Temáticas, vol.1, 2004

Agência Nacional de Vigilância Sanitária. Resolução da diretoria colegiada - RDC No48, de 25 de outubro de 2013. [acesso 25 de junho de 2018];

ABURJAI, T.; NATSHEH, F.M. Plants used in cosmetics. Phytother. Res. 2003, 17, 987-1000.

ARRIGONI BLANK, M.F, ALMEIDA, S.A., OLIVEIRA, A.C.L., Blank, A.F. Micro propagação e aclimatização de gerânio (Pelargonium graveolens $\mathrm{L}$.). Rev. bras. plantas med. vol.13 no.3 Botucatu 2011. 
[acesso 25 de junho de 2018.

B.R. RAJESWARA Rao. Rose-scented geranium (Pelargonium species): Indian and International Perspective. Journal of Medicinal and Aromatic Plant Sciences - 22 2000. [acesso 25 de junho de 2018. GUPTA, R., SINGH, A., \& PANDEY, R. A tecnologia à base de micróbios melhora os tricomas glandulares, os metabolitos secundários e os antioxidantes em Pelargonium graveolensL'Hér. Jornal da Ciência da Alimentação e Agricultura, 2016.

GOLOVATIOUK, A.; CHUCHALIN, A.G. Efficacy of an extract from Pelargonium (EPs 7630) compared to placebo in patients with acute bronchitis. Phytopharmaka, Darmstadt, v. 7, p. 1-7, 2002.

HAN, X., BEAUMONT, C., \& Stevens, N. Chemical composition analysis and in vitro biological activities of ten essential oils in human skin cells. Biochimie Open, 2017.

HIRATA L., SATO M., SANTOS C. Radicais Livres e o Envelhecimento Cutâneo.2004. [acesso 25 de junho de 2018.

JUSTYNA, K.; ANNA K.; NATALIA S.; ALINA S. Evaluation of Sebostatic Activity of Juniperus communis Fruit Oil and Pelargonium graveolens Oil Compared to Niacinamide. Cosmetics, 2017.

LIST, P.H., SCHMIDT, P.C., Phytopharmaceutical technology. CRC Press, INC., Florida - USA, 1989.

MILLER, D.M. The taxonomy of Pelargonium species and cultivars, their origins and growth in the wild. In:LIS-BALCHIN, M. Geranium and Pelargonium. London: Taylor \& Francis, p.49-79, 2002.

NEWALL, L.A., ANDERSON, L.A., PHILIPSON, J.D., (ed.) Herbal medicines a guide for health care - professionals. London: The pharmaceutical press, 1996.

OLODZIEJ, H.; KAYSER, O.; RADTKE, O. A.; KIDERLEN, A. F.; KOCH, E. Pharmacological profile of extracts of Pelargonium and their constituents. Phytomedicine, Velberga, v. 10, n. 4, p. 18-24, 2003.

PIANOVSKI, A. R. et.al. Uso do óleo de pequi (Caryocar brasiliensis) em emulsões cosméticas: desenvolvimento e avaliação de estabilidade física. Revista Brasileira de Ciências Farmacêuticas, v.44, n.2. p. 249 - 259, 2008.

RAO, B.R.R. Biomass yield, essential oil yield and essential oil composition of rose-scented geranium (Pelargoniumspecies) as influenced by row spacings and intercropping with cornmint (Mentha arvensis L. f. piperascens Malinv. Ex Holmes). Industrial Crops and Products, v.16, p.133-44, 2002.

ROMITELLI I, MARTINS, MBG. Comparação da Morfologia e da anatomia foliar entre as espécies Malva sylvestris (gerânio-aromático), Pelargonium graveolens (falsa-malva) e Pelargonium odoratissimum (gerânio-de-cheiro). Revista brasileira de plantas medicinais 2013, vol.15, n.1.

ROLIM, A.B. et.al. Accelerated chemical stability data of $o / w$ fluid emulsions containing the extract of Trichilia catigua Adr. Juss and Ptychopetalum olacoides Bentham. Revista Brasileira de Ciências Farmacêuticas, v.43, n.3, p. 405 - 412, 2007.

SAXENA, G. et al. An efficient in vitro produce for micropropagation and generation of somaclones of rose scented Pelargonium. Plant Science, v.155, p.133-40, 2000.

SHIN, S. Anti-Aspergillus activities of plant essential oils and their combination effects with ketoconazole or amphotericin B. Archives of Pharmacal. Research, Seoul, v.26, n.5, p.389-393, maio 2003.

SIMON, J.E.; CHADWICK, A.F.; CRAKER, L.E. Herbs: an indexed bibliography 1971-1980: the scientific literature on selected herbs, and aromatic and medicinal plants of the temperate zone. Hamden: Archon Books, 1984. 770p.

Secretária de Vigilância Sanitária do Ministério da Saúde. Portaria no 348 de 18 de agosto de 1997 - Manual de boas práticas de fabricação e controle para produtos de higiene pessoal, cosméticos e perfumes, 1997. 